\title{
Control and Synchronization of Hyperchaotic System based on SDRE method
}

\author{
Masoud Taleb Ziabari \\ Faculty of Engineering, Computer Engineering Group, Ahrar University, Rasht, Iran \\ Email: m.t.ziabari@gmail.com
}

Ali Reza Sahab

Faculty of Engineering, Electrical Engineering Group, Islamic Azad University, Lahijan Branch, Iran

Email: sahab@liau.ac.ir

\begin{abstract}
In this paper, stabilization and synchronization problems of the hyperchaotic system is investigated. For this reason, state dependent Riccati equation (SDRE) is used. First, stabilizer is designed by SDRE method. Then, robust controller is designed that it can stabilize hyperchaotic system with uncertainly. Finally, synchronization problem between two hyperchaotic systems is considered. The optimal controller is designed that it synchronizes two hyperchaotic systems. Numerical simulation results are presented to show the effectiveness of the proposed controllers.
\end{abstract}

Index Terms-Hyperchaotic system, state dependent Riccati equation (SDRE), optimal control, robust control, stabilization, synchronization.

\section{INTRODUCTION}

An interesting phenomenon of nonlinear systems is chaos. In recent years, studies of chaos and hyperchaos generation, control and synchronization have attracted. Therefore, various effective methods have been proposed one the past decades to achieve the control and synchronization of chaotic system, such as Robust Control [1], the sliding method control [2], linear and nonlinear feedback control [3], adaptive control [4], active control [5], backstepping control [6] and generalized backsteppig method control [7-9], ect. The purpose of the present work lies in the design of a robust optimal control system for the control and synchronization of new hyperchaotic system using the state-dependent Riccati equation (SDRE) method. The State-Dependent Riccati Equation (SDRE) techniques are general design methods that control problems involving nonlinear systems [10-14]. For a nonlinear system a form of linearization is required which is not an approximation but simply a rewriting of the mathematical model in a different form. This form, which is not unique, is then possible to obtain feedback control laws.

The rest of the paper is organized as follows: In section 2 , a new hyperchaotic system is described. In section 3, stability conditions in new hyperchaotic system are derived by SDRE method. In section 4, the stability conditions in new hyperchaotic system with uncertainly are derived by robust optimal method. In section 5, synchronization between two new hyperchaotic systems are achieved by SDRE method. Finally, section 6 isprovided conclusion of this work.

\section{HYPERCHAOTIC SYSTEM}

Recently, Dadras and Momeni proposed the new hyperchaotic system [15]. The system is described by:

$$
\begin{gathered}
\dot{x}_{1}=a x_{1}-x_{2} x_{3} \\
\dot{x}_{2}=x_{1} x_{3}-b x_{2} \\
\dot{x}_{3}=c x_{1} x_{2}-d x_{3}+g x_{1} x_{4} \\
\dot{x}_{4}=f x_{4}-h x_{2}
\end{gathered}
$$

Here $x, y, z, w$ are the state variables and $a, b, c, d, f, g, h$ are the posotive constant parameters. System (1) is hyperchaotic when $a=8, b=40, c=$ $2, d=14, f=0.05, g=5, h=0.2$. The corresponding phase portraits are depicted in Fig 1 and the state trajectory of the system (1) is displayed in Fig 2.

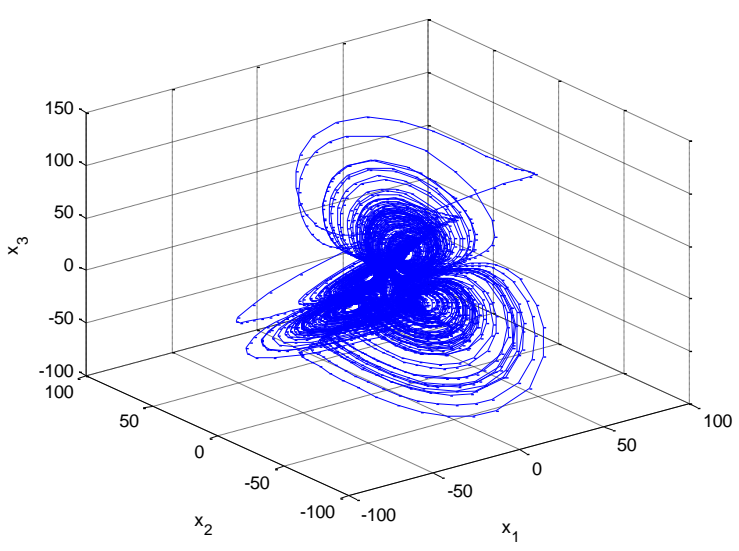

Fig. 1.phase portraits of the hyperchaotic (7). 


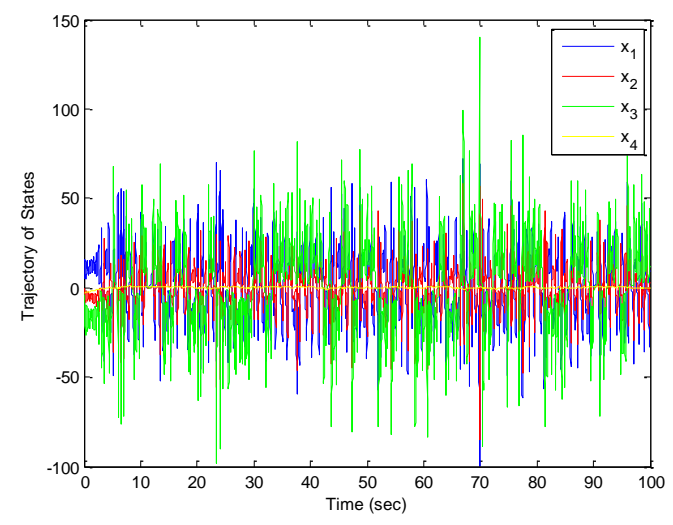

Fig. 2.state trajectory of the hyperchaotic (7).

Now, system (1) is described by state dependent Riccati equation (SDRE).

$$
\left[\begin{array}{l}
\dot{x}_{1} \\
\dot{x}_{2} \\
\dot{x}_{3} \\
\dot{x}_{4}
\end{array}\right]=\left[\begin{array}{cccc}
a & -x_{3} & 0 & 0 \\
x_{3} & -b & 0 & 0 \\
c x_{2} & 0 & -d g x_{1} \\
0 & -h & 0 & f
\end{array}\right]\left[\begin{array}{l}
x_{1} \\
x_{2} \\
x_{3} \\
x_{4}
\end{array}\right]
$$

\section{STABILIZATION OF HYPERCHAOTIC SYSTEM}

In this section, the SDRE method is applied to stabilize hyperchaotic system (2) with now parameters.

$$
\left[\begin{array}{l}
\dot{x}_{1} \\
\dot{x}_{2} \\
\dot{x}_{3} \\
\dot{x}_{4}
\end{array}\right]=\left[\begin{array}{cccc}
a & -x_{3} & 0 & 0 \\
x_{3} & -b & 0 & 0 \\
c x_{2} & 0 & -d g x_{1} \\
0 & -h & 0 & f
\end{array}\right]\left[\begin{array}{l}
x_{1} \\
x_{2} \\
x_{3} \\
x_{4}
\end{array}\right]+\left[\begin{array}{ll}
1 & 0 \\
0 & 0 \\
0 & 0 \\
0 & 1
\end{array}\right]\left[\begin{array}{l}
u_{1} \\
u_{2}
\end{array}\right]
$$

Where $\mathrm{u}_{1}, \mathrm{u}_{2}$ are control function to be determined for achieving minimize cost function (4).

$$
J=\int_{0}^{\infty}\left(x^{T}(t) Q x(t)+u^{T}(t) R u(t)\right) d t
$$

Where

$$
Q=I_{4 \times 4}, R=I_{2 \times 2}
$$

A state dependent Riccati equation (SDRE) is the solved at each point $\mathrm{X}$ along the trajectory to obtain a nonlinear feedback controller of the form (6), where $P(t)$ is the solution of the SDRE.

$$
\begin{gathered}
u(t)=-k(t) x(t) \\
k(t)=R^{-1} B^{T}(t) P(t)
\end{gathered}
$$

$\dot{P}(t)+P(t)(A(x(t))+\alpha I)+\left(A^{T}(x(t))+\alpha I\right) P(t)+$ $Q-P(t) B(t) R^{-1} B^{T}(t) P(t)=0$

Where scaler $\alpha$ is a design parameter [17]. We choose $\alpha=20$. As can be seen, the SDRE method produces a stabilizing solution. The time response of $\mathrm{x}_{1}, \mathrm{x}_{2}, \mathrm{x}_{3}, \mathrm{x}_{4}$ states for system (3) is shown in Fig 3. The time response of control inputs $\mathrm{u}_{1}, \mathrm{u}_{2}$ is shown in Fig 4 .
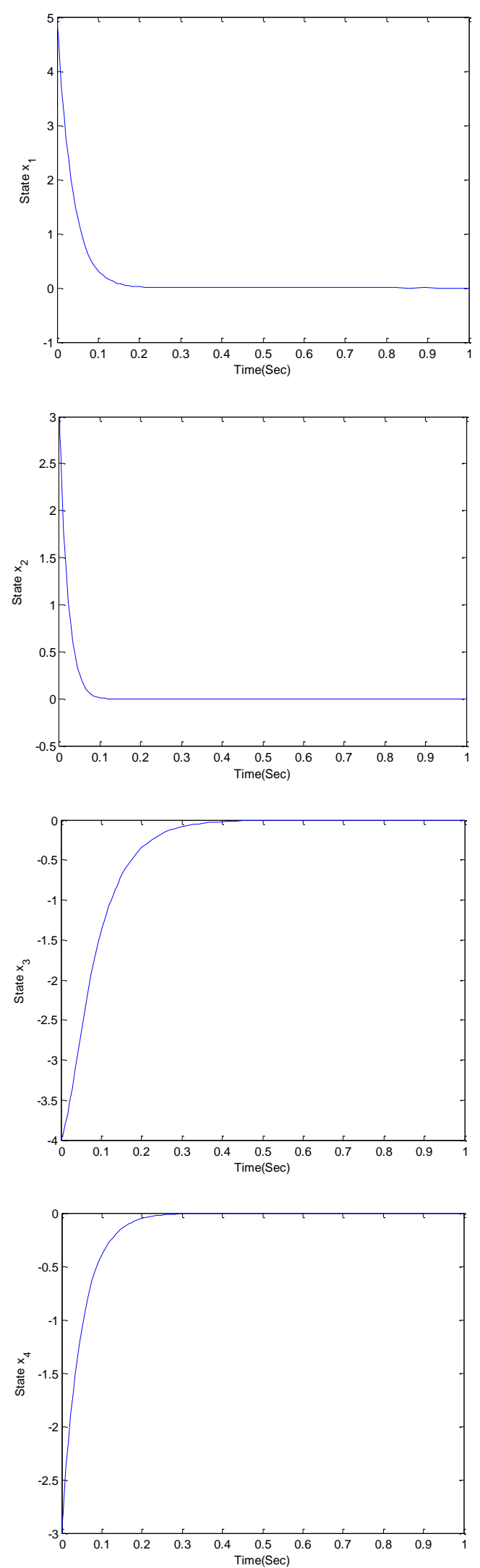

Fig. 3.the time response of signals $\left(\mathrm{x}_{1}, \mathrm{x}_{2}, \mathrm{x}_{3}, \mathrm{x}_{4}\right)$ for system (3). 

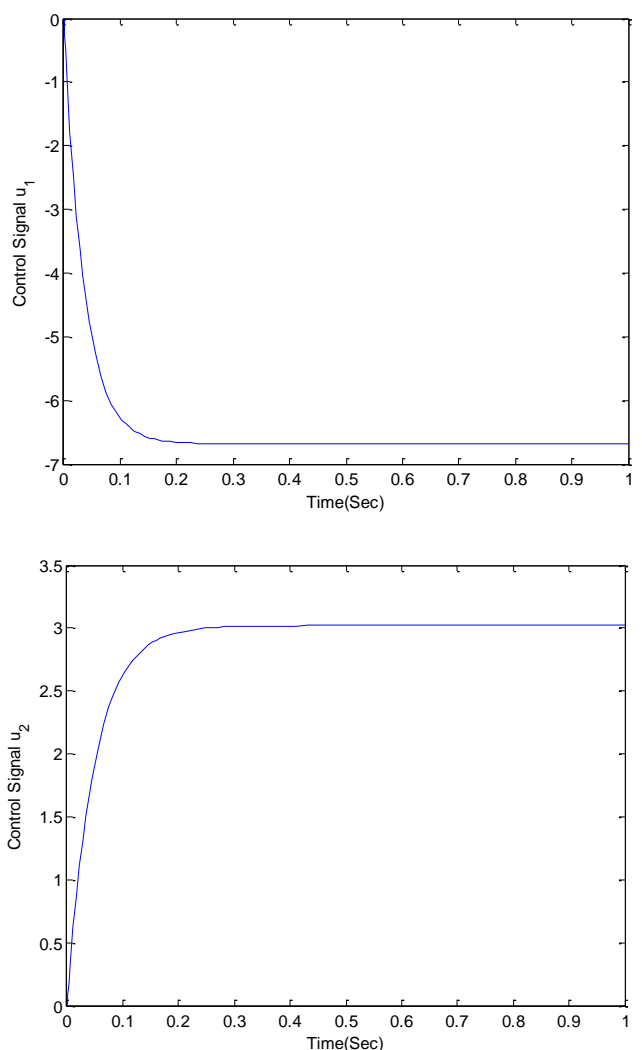

Fig. 4.the time response of the control inputs $\left(\mathrm{u}_{1}, \mathrm{u}_{2}\right)$.

\section{STABILIZATION OF HYPERCHAOTIC SYSTEM WITH UNCERTAINLY}

In practical situations, some or all of system parameter can not be exactly know in advance. We assume the system (3) with uncertainly.

$$
\left[\begin{array}{l}
\dot{x}_{1} \\
\dot{x}_{2} \\
\dot{x}_{3} \\
\dot{x}_{4}
\end{array}\right]=\left[\begin{array}{cccc}
a+\theta_{1}-x_{3} & 0 & 0 \\
x_{3} & -b & 0 & 0 \\
c x_{2} & 0 & -d & g x_{1} \\
0 & -h & 0 & f+\theta_{2}
\end{array}\right]\left[\begin{array}{l}
x_{1} \\
x_{2} \\
x_{3} \\
x_{4}
\end{array}\right]+\left[\begin{array}{ll}
1 & 0 \\
0 & 0 \\
0 & 0 \\
0 & 1
\end{array}\right]\left[\begin{array}{l}
u_{1} \\
u_{2}
\end{array}\right]
$$

Where $\theta_{1}, \theta_{2}$ are uncertainly in system and $\theta_{\mathrm{i}} \in$ $[0,30], i=1,2$. Now, robust controller is designed by presented method in [16]. For this reason, states matrix is analysed as follows:

$$
\begin{aligned}
& {\left[\begin{array}{cccc}
a+\theta_{1}-x_{3} & 0 & 0 \\
x_{3} & -b & 0 & 0 \\
c x_{2} & 0 & -d & g x_{1} \\
0 & -h & 0 & f+\theta_{2}
\end{array}\right]-\left[\begin{array}{cccc}
a & -x_{3} & 0 & 0 \\
x_{3} & -b & 0 & 0 \\
c x_{2} & 0 & -d g x_{1} \\
0 & -h & 0 & f
\end{array}\right]=} \\
& {\left[\begin{array}{ll}
1 & 0 \\
0 & 0 \\
0 & 0 \\
0 & 1
\end{array}\right] \phi(\theta)=B \phi(\theta)}
\end{aligned}
$$

Where

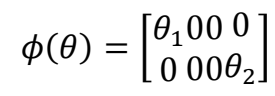

System (9) is rewrote as follows:

$$
\begin{aligned}
& {\left[\begin{array}{l}
\dot{x}_{1} \\
\dot{x}_{2} \\
\dot{x}_{3} \\
\dot{x}_{4}
\end{array}\right]=\left[\begin{array}{cccc}
a & -x_{3} & 0 & 0 \\
x_{3}-b & 0 & 0 \\
c x_{2} & 0 & -d & g x_{1} \\
0 & -h & 0 & f
\end{array}\right]\left[\begin{array}{l}
x_{1} \\
x_{2} \\
x_{3} \\
x_{4}
\end{array}\right]+\left[\begin{array}{ll}
1 & 0 \\
0 & 0 \\
0 & 0 \\
0 & 1
\end{array}\right]\left[\begin{array}{l}
u_{1} \\
u_{2}
\end{array}\right]+} \\
& B \phi(\theta)\left[\begin{array}{l}
x_{1} \\
x_{2} \\
x_{3} \\
x_{4}
\end{array}\right]
\end{aligned}
$$

We must find the control signals (6) that it stabilizes the system (12) wwithuncertainly $\theta_{i}, i=1,2$. This problem is solved by optimal control of system (3) that it minimizes cost function (13) [16].

$$
J=\int_{0}^{\infty}\left(x^{T}(t) F x(t)+x^{T}(t) x(t)+u^{T}(t) R u(t)\right) d t
$$

Where F matrix is

$$
\begin{aligned}
& \phi^{T}(\theta) \phi(\theta) \leq F
\end{aligned}
$$

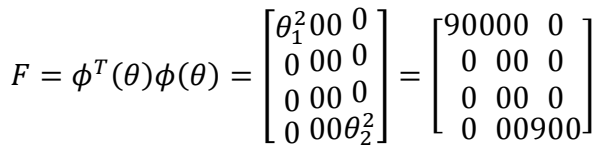

Again, the Riccati equation is solved and the optimal feedback control (6) is obtained. The time response of $\mathrm{x}_{1}, \mathrm{x}_{2}, \mathrm{x}_{3}, \mathrm{x}_{4}$ states for system (9) is shown in Fig 5. The time response of control inputs $u_{1}, u_{2}$ is shown in Fig 6 .
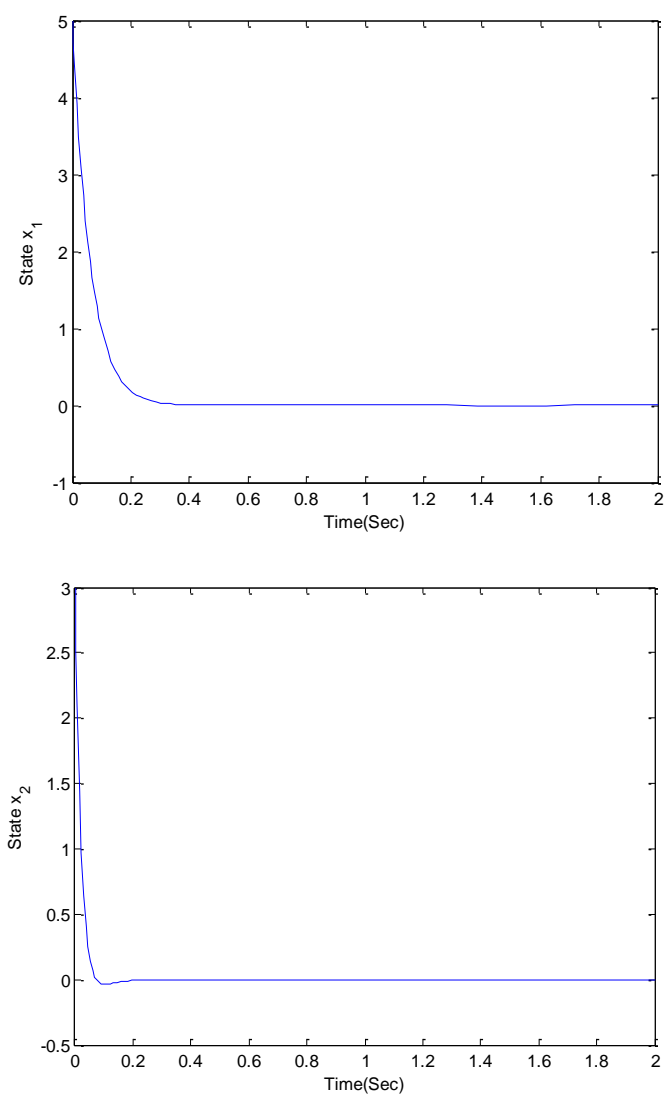

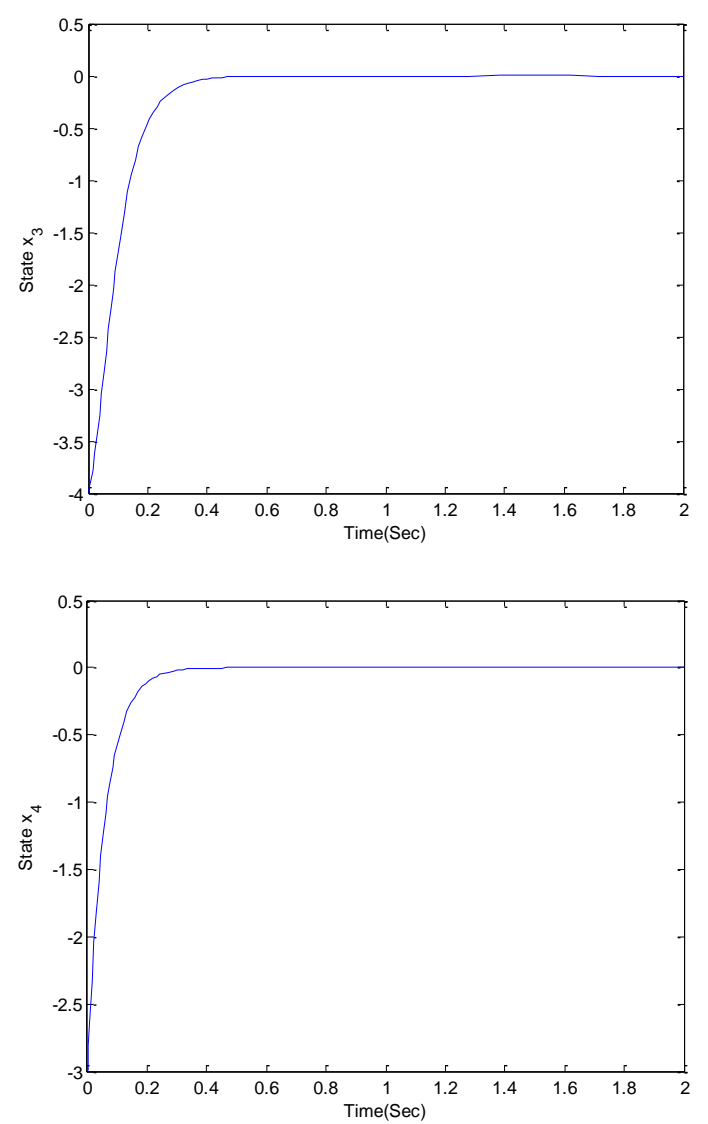

Fig. 5.the time response of signals $\left(\mathrm{x}_{1}, \mathrm{x}_{2}, \mathrm{x}_{3}, \mathrm{x}_{4}\right)$ for system (9).
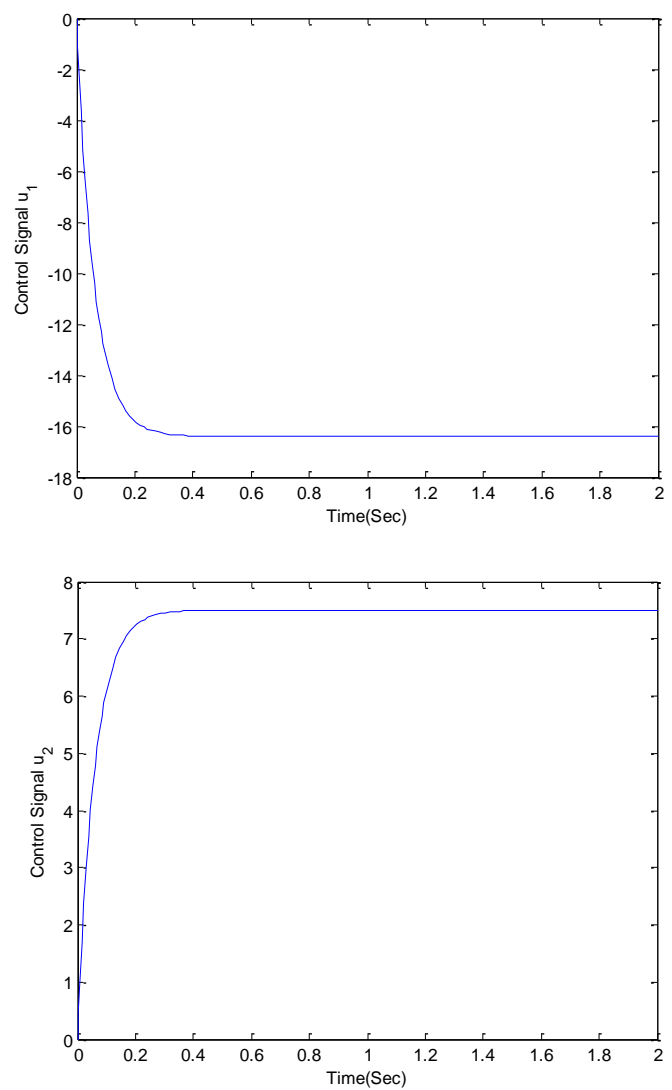

Fig. 6.the time response of the control inputs $\left(\mathrm{u}_{1}, \mathrm{u}_{2}\right)$.

\section{SYNCHRONIZATION OF HYPERCHAOTIC SYSTEM}

In this section, the SDRE method is applied to synchronize two hyperchaoticsystem. Suppose the drive system takes the following form

$$
\begin{gathered}
\dot{x}_{1}=a x_{1}-y_{1} z_{1} \\
\dot{y}_{1}=x_{1} z_{1}-b y_{1} \\
\dot{z}_{1}=c x_{1} y_{1}-d z_{1}+g x_{1} w_{1} \\
\dot{w}_{1}=f w_{1}-h y_{1}
\end{gathered}
$$

And the response system is given as follows

$$
\begin{aligned}
& \dot{x}_{2}=a x_{2}-y_{2} z_{2}+u_{1}(t) \\
& \dot{y}_{2}=x_{2} z_{2}-b y_{2}+u_{2}(t) \\
\dot{z}_{2}= & c x_{2} y_{2}-d z_{2}+g x_{2} w_{2}+u_{3}(t) \\
& \dot{w}_{2}=f w_{2}-h y_{2}+u_{4}(t)
\end{aligned}
$$

Where $\mathrm{u}_{1}, \mathrm{u}_{2}, \mathrm{u}_{3}, \mathrm{u}_{4}$ are control inputs. Define state errors between system (16) and (17) as follows

$$
\begin{aligned}
& e_{x}=x_{2}-x_{1} \\
& e_{y}=y_{2}-y_{1} \\
& e_{z}=z_{2}-z_{1} \\
& e_{w}=w_{2}-w_{1}
\end{aligned}
$$

We obtain the following error dynamical system by subtracting the drive system (16) from the response system (17)

$$
\begin{gathered}
\dot{e}_{x}=a e_{x}-e_{y} e_{z}+z_{1} e_{y}+y_{1} e_{y}+u_{1}(t) \\
\dot{e}_{x}=e_{x} e_{z}-b e_{y}-x_{1} e_{z}-z_{1} e_{x}+u_{2}(t) \\
\dot{e}_{z}=c e_{x} e_{y}-d e_{z}+g e_{x} e_{w}-c x_{1} e_{y}-c y_{1} e_{x}-g x_{1} e_{w} \\
-g w_{1} e_{x}+u_{3}(t) \\
\dot{e}_{w}=f e_{w}-h e_{y}+u_{4}(t)
\end{gathered}
$$

Error dynamical system (19) is rewrote as follows

$$
\left[\begin{array}{c}
\dot{e}_{x} \\
\dot{e}_{y} \\
\dot{e}_{z} \\
\dot{e}_{w}
\end{array}\right]=A\left[\begin{array}{c}
e_{x} \\
e_{y} \\
e_{z} \\
e_{w}
\end{array}\right]+\Delta A\left[\begin{array}{c}
e_{x} \\
e_{y} \\
e_{z} \\
e_{w}
\end{array}\right]+B\left[\begin{array}{l}
u_{1} \\
u_{2} \\
u_{3} \\
u_{4}
\end{array}\right]
$$

Where

$$
\begin{aligned}
A & =\left[\begin{array}{cccc}
a & -e_{z} & 0 & 0 \\
e_{z} & -b & 0 & 0 \\
c e_{y} & 0 & -d g e_{x} \\
0 & -h & 0 & f
\end{array}\right] \\
\Delta A & =\left[\begin{array}{cccc}
0 & z_{1} & y_{1} & 0 \\
-z_{1} & 0 & -x_{1} & 0 \\
-c y_{1}-g w_{1}-c x_{1} & 0 & -g x_{1} \\
0 & 0 & 0 & 0
\end{array}\right] \\
B & =\left[\begin{array}{l}
1000 \\
0100 \\
0010 \\
0001
\end{array}\right]
\end{aligned}
$$

We can rewrite $\Delta \mathrm{A}$ matrix as follows 


$$
\begin{gathered}
\Delta A=\left[\begin{array}{cccc}
0 & z_{1} & y_{1} & 0 \\
-z_{1} & 0 & -x_{1} & 0 \\
-c y_{1}-g w_{1}-c x_{1} & 0 & -g x_{1} \\
0 & 0 & 0
\end{array}\right]=\left[\begin{array}{c}
1000 \\
0100 \\
0010 \\
0001
\end{array}\right] \\
\Delta A=B \phi(X)
\end{gathered}
$$

Where $X=[x, y, z, w]^{T}$. Substituting (22) into (20), the error dynamics is obtained.

$$
\left[\begin{array}{c}
\dot{e}_{x} \\
\dot{e}_{y} \\
\dot{e}_{z} \\
\dot{e}_{w}
\end{array}\right]=A\left[\begin{array}{c}
e_{x} \\
e_{y} \\
e_{z} \\
e_{w}
\end{array}\right]+B\left[\begin{array}{l}
u_{1} \\
u_{2} \\
u_{3} \\
u_{4}
\end{array}\right]+B \phi(X)\left[\begin{array}{l}
e_{x} \\
e_{y} \\
e_{z} \\
e_{w}
\end{array}\right]
$$

We obtain optimal feedback control (6) that it minimizes the cost function (13) [16]. The F matrix is obtained.

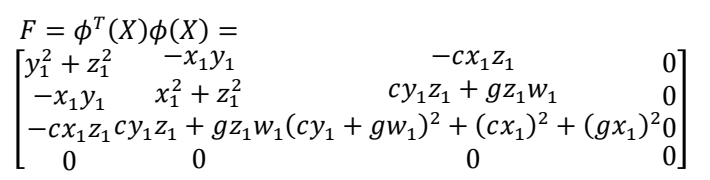

Again, the Riccati equation is solved and the optimal feedback control (6) is obtained. Synchronization errors $\mathrm{e}_{\mathrm{x}}, \mathrm{e}_{\mathrm{y}}, \mathrm{e}_{\mathrm{z}}, \mathrm{e}_{\mathrm{w}}$ in hyperchaotic system are shown in Fig 7. The time response of $\mathrm{x}, \mathrm{y}, \mathrm{z}, \mathrm{w}$ states for drive system (16) and response system (17) is shown in Fig 8. The time response of the control inputs $\mathrm{u}_{1}, \mathrm{u}_{2}, \mathrm{u}_{3}, \mathrm{u}_{4}$ for the synchronization of hyperchaotic system is shown in Fig 9 .
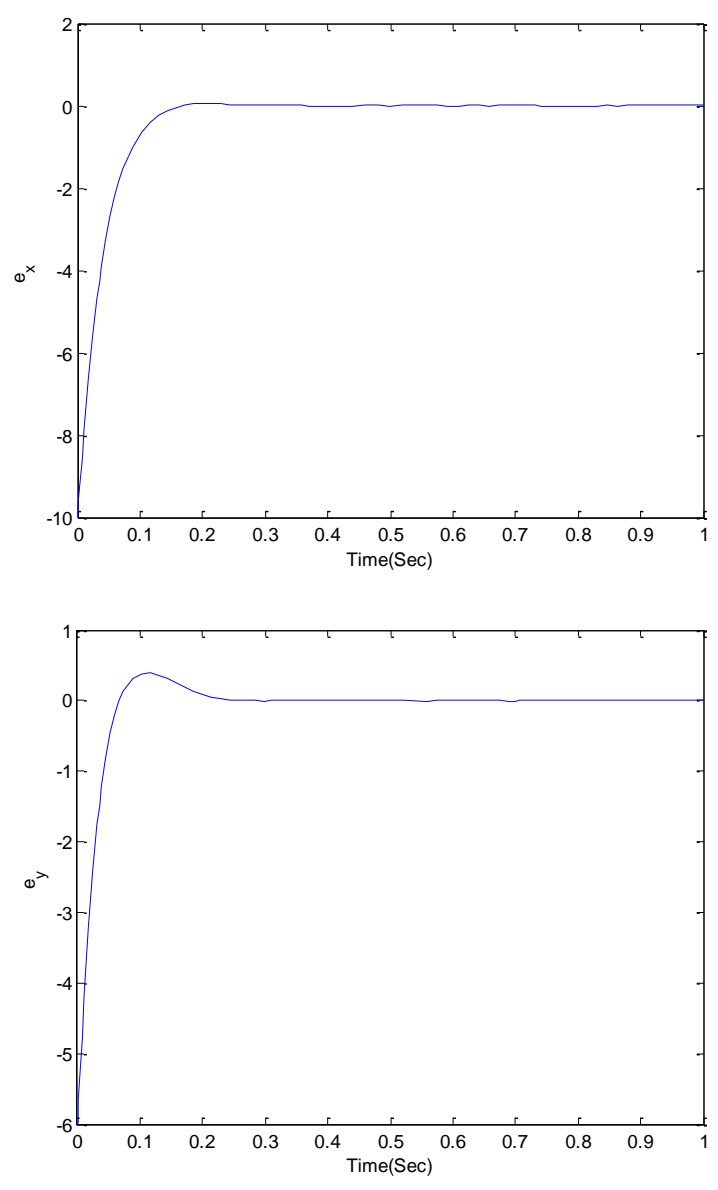
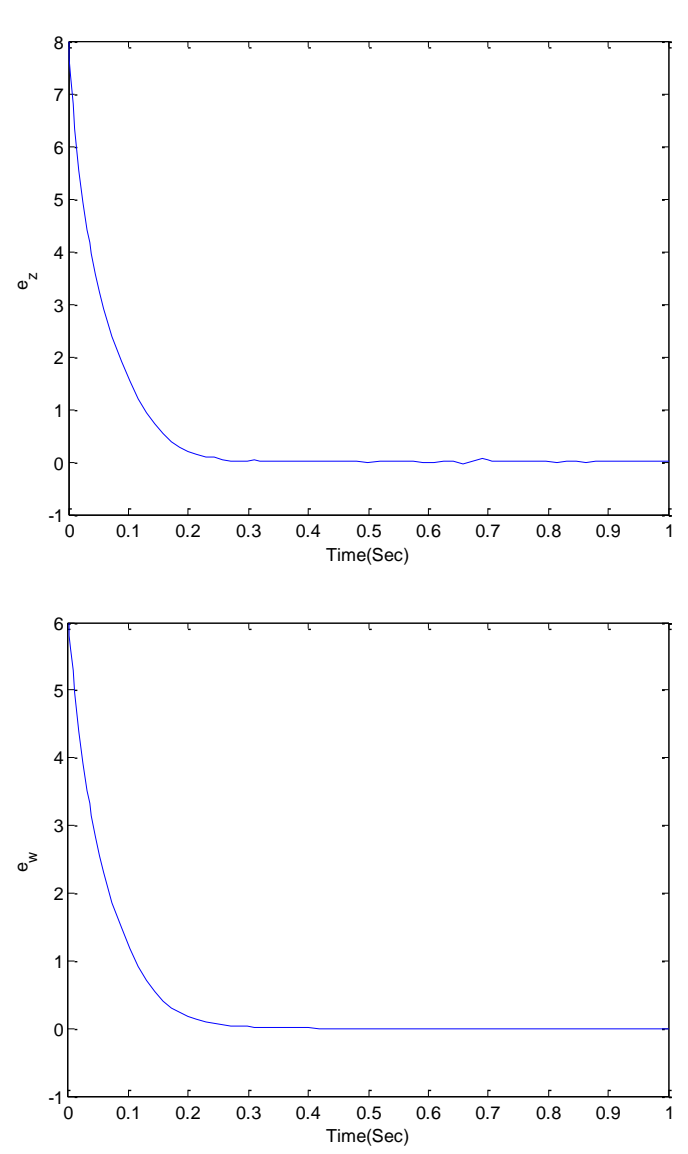

Fig. 7.synchronization errors $\left(\mathrm{e}_{\mathrm{x}}, \mathrm{e}_{\mathrm{y}}, \mathrm{e}_{\mathrm{z}}, \mathrm{e}_{\mathrm{w}}\right)$ in drive system (16) and response system (17).
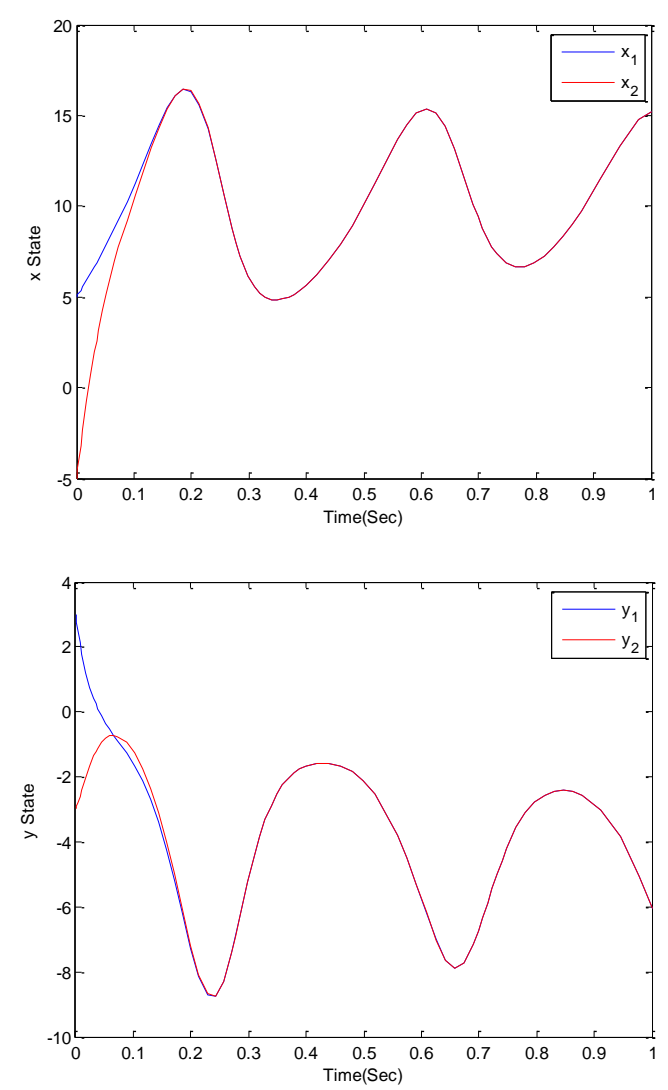

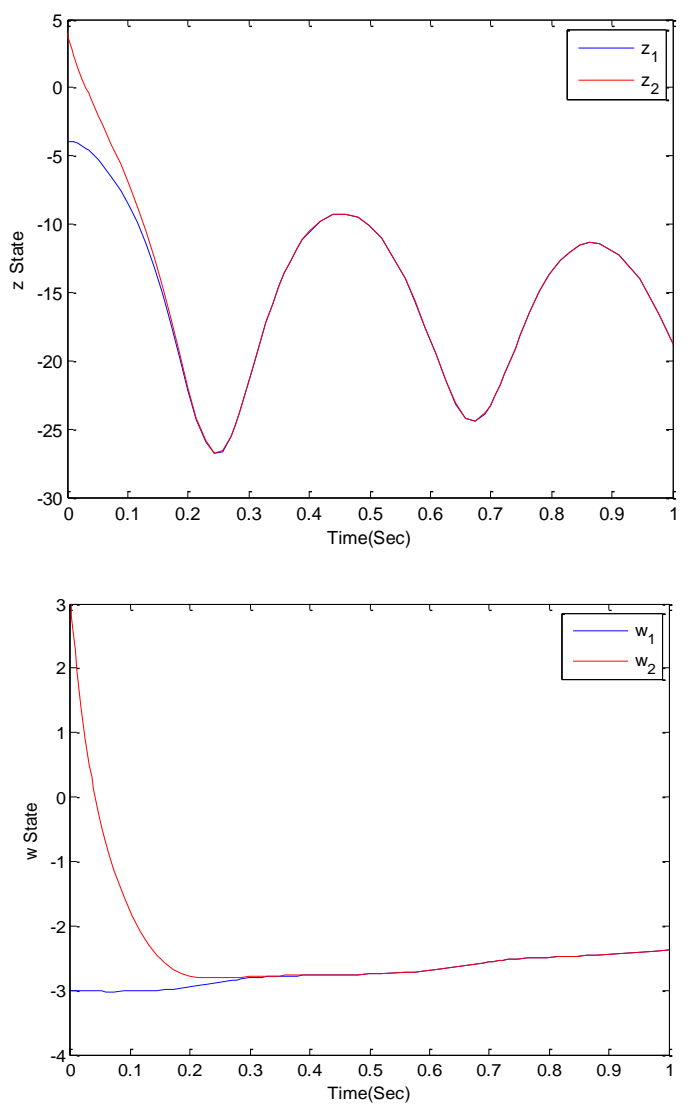

Fig. 8.the time response of signals $(\mathrm{x}, \mathrm{y}, \mathrm{z}, \mathrm{w})$ for drive system (16) and response system (17).
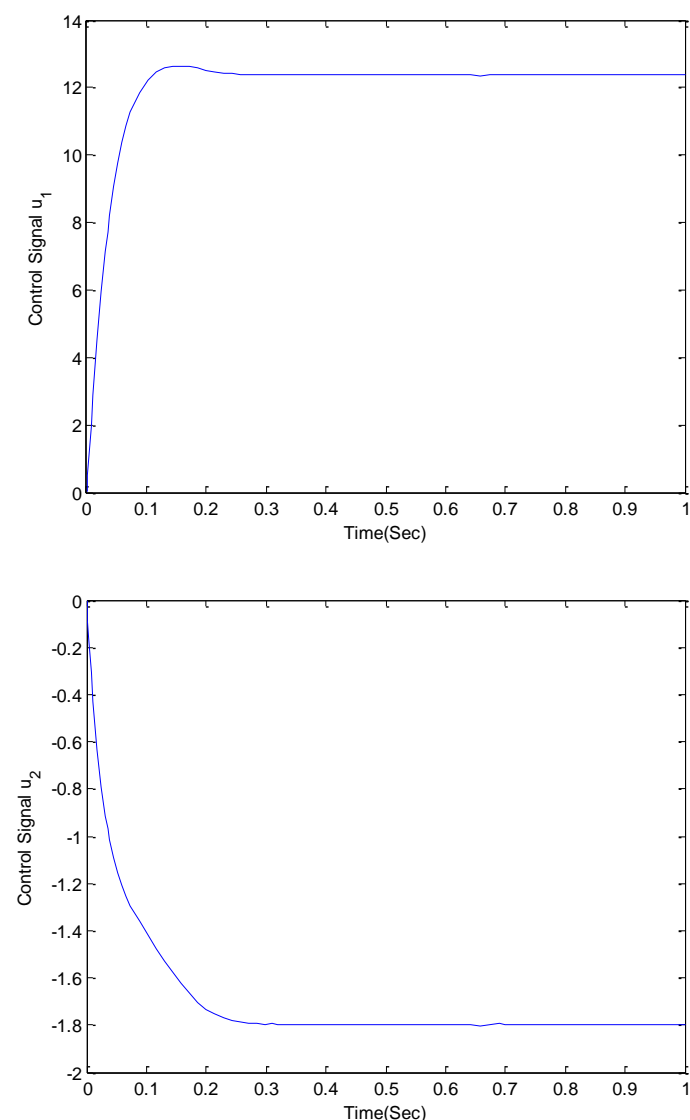
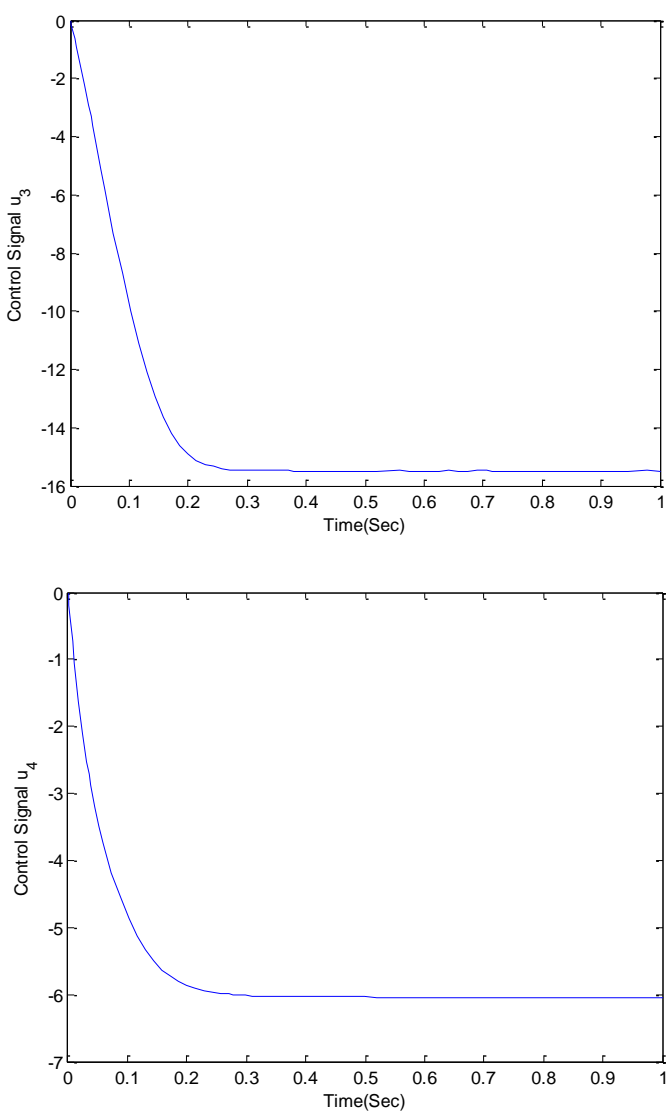

Fig. 9.the time response of the control inputs $\left(\mathrm{u}_{1}, \mathrm{u}_{2}, \mathrm{u}_{3}, \mathrm{u}_{4}\right)$.

\section{CONCLUSION}

In this paper, stabilization and synchronization problem of the new hyperchaotic system was investigated. For this reason, state dependent Riccati equation (SDRE) was used. This method was applied to new hyperchaotic system in three ways. Stabilized system with know parameters, stabilized system with unknow parameters, sysnchronized system. In every way, simulations proved abilities of method.

\section{REFERENCES}

[1] Chao-Chung Peng, Chieh-Li Chen. Robust chaotic control of Lorenz system by backstepping design. Chaos, Solitons and Fractals 37 (2008) 598-608.

[2] Cheng-Chi Wang, Neng-Sheng Pai, Her-TerngYau. Chaos control in AFM system using sliding mode control by backstepping design. Commun Nonlinear SciNumerSimulat 15 (2010) 741-751.

[3] Faqiang Wang, Chongxin Liu. A new criterion for chaos and hyperchaos synchronization using linear feedback control. Physics Letters A 360 (2006) 274-278.

[4] Yongguang Yu, Suochun Zhang. Adaptive backstepping synchronization of uncertain chaotic system. Chaos, Solitons and Fractals 21 (2004) 643-649.

[5] Sinha SC, Henrichs JT, Ravindra BA. A general approach in the design of active controllers for nonlinear systems exhibiting chaos. Int J Bifurcat Chaos 2000; 10(1):165-78. 
[6] M.T. Yassen. Chaos control of chaotic dynamical systems using backstepping design. Chaos, Solitons and Fractals 27 (2006) 537-548.

[7] Ali Reza Sahab and Mohammad Haddad Zarif. Improve Backstepping Method to GBM. World Applied Sciences Journal 6 (10): 1399-1403, 2009, ISSN 1818-4952.

[8] Sahab, A.R. and M. Haddad Zarif. Chaos Control in Nonlinear Systems Using the Generalized Backstopping Method. American J. of Engineering and Applied Sciences 1 (4): 378-383, 2008, ISSN 1941-7020.

[9] Ali Reza Sahab, MasoudTalebZiabari, Seyed Amin SadjadiAlamdari. Chaos Control via Optimal Generalized Backstepping Method. International Review of Electrical Engineering (I.R.E.E), Vol.5, n.5.

[10] Mugdha S. Naik, Sahjendra N. Singh, State-dependent Riccati equation-based robust dive plane control of AUV with control constraints, Ocean Engineering 34 (2007) $1711-1723$.

[11] Insu Chang and Soon-Jo Chung, Exponential Stability Region Estimates for the State-Dependent Riccati Equation Controllers, Joint 48th IEEE Conference on Decision and Control and 28th Chinese Control Conference Shanghai, P.R. China, December 16-18, 2009.

[12] TayfunÇimen, State-Dependent Riccati Equation (SDRE) Control: A Survey, Proceedings of the 17th World Congress The International Federation of Automatic Control Seoul, Korea, July 6-11, 2008.

[13] A. Jayaram, M. Tadi, Synchronization of chaotic systems based on SDRE method, Chaos, Solitons and Fractals 28 (2006) 707-715.

[14] Muhammad KashifSiddiq, Fang Jian Cheng, and Yu Wen Bo, State Dependent Riccati Equation Based Roll Autopilot for $122 \mathrm{~mm}$ Artillery Rocket, World Academy of Science, Engineering and Technology 722012.

[15] Sara Dadras, Hamid Reza Momeni, Four-scroll hyperchaos and four-scroll chaos evolved from a novel 4D nonlinear smooth autonomous system, Physics Letters A 374 (2010) 1368-1373.

[16] Feng Lin, Robust Control Design An Optimal Control Approach, ISBN 978-0-470-03191-9.

[17] H. Beikzadeh, H. D. Taghirad, Exponential Nonlinear Observer Design Based on Differential State-Dependent Riccati Equation, Journal of Control, Vol. 4, No. 4, Winter 2011, ISSN 2008-8345.

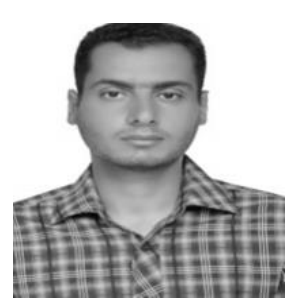

Masoud Taleb Ziabari.Received the B.S. in computer hardware from Islamic Azad University, Yazd, Iran in 2005. He Received the M.S. student in major of Mechatronic in Islamic Azad University Qazvin Branch, Qazvin, Iran. His research interests include nonlinear control and intelligent systems.

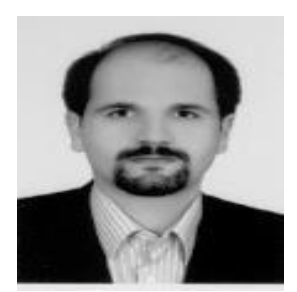

Ali Reza Sahab.Received the B.S. in control engineering from KNT the University of Technology, Tehran, Iran in 2001 and the M.S. and Ph.D. degrees in control engineering from Shahrood University of Technology, Shahrood, Iran in 2003 and 2009 respectively.He is a staff member of Electrical Group, Engineering Faculty of Islamic Azad University, Lahijan Branch. His research interests include nonlinear control and intelligent systems.

How to cite this paper: Masoud Taleb Ziabari, Ali Reza Sahab,"Control and Synchronization of Hyperchaotic System based on SDRE Method", IJIEEB, vol.6, no.3, pp.44-50, 2014. DOI: 10.5815/ijieeb.2014.03.07 